indicators to using job planning' as the means of determining a doable consultant job.

\section{Revised joined guidance}

The newly issued revised joint guidance continues this approach. The main authors are again the Royal College of Psychiatrists, NIMHE, the NHS Confederation, and the Department of Health. Although foundation trusts are able to set their own recruitment processes, they have agreed the guidance and can be expected to follow it. Population norms and indicative case-loads have been abandoned in favour of team working and job planning. The place of the consultant psychiatrist within the team in bringing specialist expertise to complex treatment decision-making is highlighted, but the emphasis is on the capacity and skill-mix of the team and not of any individual within it. The 'creating capable teams' approach and consultant job-planning are both seen as pivotal in achieving this.

College advice continues to play an important part in ensuring that consultant posts are viable. The process is clearly laid out for employers, with a description of the differing functions of regional advisors, specialty regional representatives and College assessors. There is also an appendix in which each of the College faculties has produced an outline of the role of a consultant psychiatrist in its specialty. These describe the different functional teams that exist within each specialty and how the consultant contributes to them.

The guidance also gives much helpful advice on the process of recruitment and particularly the many ways in which users and carers can participate in the selection process. There are a number of examples of successful involvement of users and carers at all stages.

Finally, there are useful flowcharts and templates for the creation of model job descriptions and person specifications. Much of these are, however, deliberately left blank in order for a service to be able to describe the specific model of working within which its consultant posts exists.

Any document giving guidance on employment or workforce only has a limited shelf life. The plan is that this revised guidance will be maintained in web-based form to permit easy updating. It will be fully reviewed again in 3 years' time when perhaps we will indeed have moved on to having a truly creative capable workforce.

\section{About the author}

Andrew Clark is the Royal College of Psychiatrists Workforce Lead and North West Regional Advisor, Lead Consultant and Honorary Senior Lecturer, Young Persons' Directorate, Greater Manchester West Mental Health NHS Foundation Trust.

\section{References}

1 Department of Health, NHS Confederation, Royal College of Psychiatrists, National Institute for Mental Health in England. Joint Guidance on the Employment of Consultant Psychiatrists. Department of Health, 2009.

2 Royal College of Psychiatrists, NHS Confederation, National Mental Health Partnership. Joint Guidance on the Employment of Consultant Psychiatrists. Department of Health, 2005.

3 Royal College of Psychiatrists. Model Consultant Job Descriptions and Recommended Norms. Occasional Paper 55. Royal College of Psychiatrists, 2002

\title{
FREDA: a human rights-based approach to healthcare
}

\author{
Martin J. Curtice, ${ }^{1}$ Tim Exworthy ${ }^{2}$
}

The Psychiatrist (2010), 34, 150-156, doi: 10.1192/pb.bp.108.024083

${ }^{1}$ Hollyhill Unit, Birmingham, ${ }^{2}$ Memorial Hospital, Oxleas NHS Foundation Trust, London

Correspondence to Martin J. Curtice (mjrc@ukonline.co.uk)
Summary The introduction of the Human Rights Act 1998 in the UK has not led to widespread knowledge and understanding in patient and carer groups, healthcare professionals or at an organisational level. This knowledge deficit has been recognised by government bodies and other agencies, which has led to the introduction of a bottom-up human rights-based approach that can be used by individuals and organisations alike in everyday practice. It avoids the need to have technical knowledge of the Human Rights Act and associated case law and is based upon concepts that underpin all the articles of the Act. The human rights-based approach is the process by which human rights can be protected by adherence to underlying core values of fairness, respect, equality, dignity and autonomy, or FREDA.

Declaration of interest M.J.C. is a member of the Special Committee for Human Rights, Royal College of Psychiatrists; T.E. chairs the Special Committee for Human Rights and is a member of the Department of Health's Advisory Group on Human Rights in Healthcare. 
The Human Rights Act 1998 came into force in October 2000 and incorporates most of the rights protected under the European Convention on Human Rights (ECHR). It must be considered in all UK courts, including mental health review tribunals. Public authorities, which include National Health Service (NHS) bodies, have a duty to take steps to protect ('positive obligations') the human rights of individuals.

Avoiding violation of the ECHR could be construed as a negative approach towards these civil and political rights. A more constructive endeavour is to embed human rights values within the culture of the organisation. In this way subsequent policy and decision-making is framed around such values. However, more recently a coordinated approach can be discerned in healthcare, which adopts a human rights-based approach. This approach to healthcare is based on the premise that ignoring or violating a person's human rights has a detrimental effect on their health and, conversely, using this approach can improve health outcomes and deliver better quality, 'person-centred' healthcare.

The Department of Health ${ }^{1}$ has identified five key aims of a human rights-based approach to healthcare:

1 putting human rights principles and standards at the heart of policy and planning;

2 empowering staff and patients with knowledge, skills and organisational leadership and commitment to achieve human rights-based approach;

3 enabling meaningful involvement and participation of all key stakeholders;

4 ensuring clear accountability throughout the organisation; 5 non-discrimination and attention to vulnerable groups.

Such an approach is not completely revolutionary. For example, in 2001 the National Service Framework for Older People ${ }^{2}$ advocated a 'cultural change so that all older people and their carers are always treated with respect, dignity and fairness'. This has been developed into the 'Dignity in Care' campaign promoting dignity towards older people in health or social care settings and acknowledging that organisations which centre service delivery around the dignity of the recipient can be regarded as high-quality. ${ }^{3}$

The human rights-based approach is a bottom-up approach (as opposed to the top-down variety requiring detailed knowledge of the Human Rights Act articles and associated case law) whereby the concepts which underpin all the articles of the Act are operationalised and put into everyday practice without the need for technical knowledge of the Act. Although some advocate making explicit the links between human rights values and the Act, ${ }^{4}$ we set out to demonstrate in this paper that clinicians should already be familiar with these values even if the language seems unusual. We will show that echoes of the human rights principles can be found in the existing clinical literature, although there will be a significant emphasis on mental health literature (as the principles can easily apply to all medical specialties). Moreover, it has now been proposed that revalidation of medical practitioners' licences to practise should involve patients in helping to define good healthcare with a focus on treating patients with respect and dignity. ${ }^{5}$

\section{The FREDA principles}

In essence, the human rights-based approach is the process by which human rights can be protected in clinical and organisational practice by adherence to the underlying core values of fairness, respect, equality, dignity and autonomy (FREDA). These principles are the basics of good clinical care sewn into what clinicians already do on a daily basis, a view espoused in the latest edition of the College's Good Psychiatric Practice.

Although it is helpful to clarify the meaning attached to each principle, it is also artificial to consider the core principles separately since a human rights-based approach essentially involves all five values being brought to bear on a particular issue. These principles are used to inform decisions, not to determine them. All of the principles must inform each decision, but the weight given to each principle in reaching a particular conclusion will depend on the issues under consideration. It may be the case that in making some decisions a greater weight should be given to some of the principles over others. That is not to say that in making a decision any of the principles should be disregarded.

\section{Fairness}

This principle demands that due consideration is afforded to the person's opinion, giving them the opportunity to have that point of view expressed, listened to and weighed, alongside other factors relevant to the decision to be taken. The process should also be free of arbitrary considerations, thereby imparting a degree of certainty to the process and allowing others to determine how they might be treated in similar circumstances. There is also a link with the principle of equality (see later) in ensuring that the decision-making is free of discriminatory practices.

\section{Clinical illustrations}

The principle of fairness is relevant when concerning the lawful detention of individuals and equally the de facto detention of 'Bournewood'-adherent incapacitated individuals who lack the capacity to consent to or refuse admission to hospital, for example, some individuals with intellectual disability and the elderly. The Mental Health Act 1983 sets out the purpose and procedure for formal detentions and the safeguards it contains introduce certainty and procedural rigour while removing arbitrariness from the process. In the Bournewood case, the European Court of Human Rights held that such safeguards were lacking and Article 5 of the ECHR, guaranteeing the person's right to liberty, had been violated. ${ }^{7}$ The UK government has since amended the Mental Capacity Act 2005 with the introduction of 'deprivation of liberty safeguards' to ensure a person is only deprived of their liberty following a structured consideration of their needs and there is a regular review of its necessity. ${ }^{8}$

Fairness is directly linked to Article 6 of the ECHR, the right to a fair trial. A mental health review tribunal hearing, for example, contains several procedures that need to be considered during the decision-making process. The tribunal panel is independent of the detaining authority and impartial. The detained person and a legal representative are present 
and given an opportunity to set out their case and challenge the evidence against the person before the decision is made. The procedure also requires disclosure of relevant documents. In short, decisions and decision-making processes should be fair, open, timely and impartial. In the case of mental health review tribunals, there are tribunal rules ${ }^{9}$ setting out a degree of procedural rigour to help ensure fairness in the hearings process.

\section{Respect}

Respect is the objective, unbiased consideration and regard for the rights, values, beliefs and property of other people. Respect applies to the person as well as their value systems and implies that these are fully considered before decisions which may overrule them are taken. Respect is construed from the actions shown to an individual by others and can be demonstrated by courteous communication, which imbues the person with a sense of being valued through taking time to get to know them as individuals, not as 'numbers' or 'conditions': person-centred care. ${ }^{10}$ Organisational bureaucracy and administrative burdens can act as powerful obstacles to achieving this.

The Revised Code of Practice to the Mental Health Act ${ }^{11}$ includes respect as one of the fundamental principles guiding implementation of the Act. The principle demands that

'People taking decisions under the Act must recognise and respect the diverse needs, values and circumstances of each patient, including their race, religion, culture, gender, age, sexual orientation and any disability. They must consider the patient's views, wishes and feelings (whether expressed at the time or in advance), so far as they are reasonably ascertainable, and follow those wishes wherever practicable and consistent with the purpose of the decision.'

The wording of the second sentence is similar to the language of the 'best interests' test within the Mental Capacity Act 2005, reminding clinicians that the respect principle survives any loss or impairment of capacity of the individual being offered care.

Guidance from the General Medical Council on consent, ${ }^{12}$ under the principle of partnership, emphasises the need to facilitate and respect patients' treatment decisions as one of the core principles in providing care. The Royal College of Psychiatrists has also provided guidance in this area. ${ }^{13,14}$ Of particular relevance in the 2004 edition of the College's Good Psychiatric Practice ${ }^{13}$ is the section on the 'trusting relationship', where it states that 'The psychiatrist will... respect patients' privacy and dignity... (and)... be mindful of the vulnerability of some patients to exploitation within the therapeutic relationship'.

\section{Clinical illustrations}

Respect for privacy (under Article 8 of the Human Rights Act) has been termed 'the ultimate embodiment of a right to be free from external intervention, ${ }^{15}$ and may offer some measure of protection in situations of enforced psychiatric treatment. ${ }^{16}$ Article 8 promotes respect for the person and physical integrity, respect for an individual's home and for privacy. Private life is interpreted broadly to include 'issues such as personal choices, relationships, physical and mental well-being, access to personal information and participation in community life'. ${ }^{17}$

In healthcare the 'fundamental importance' of respecting the 'crucial... and vital principle' of confidentiality and privacy of medical information has been clearly stated by the courts. ${ }^{18}$ However, there are circumstances when it may be necessary to share or disclose confidential information, even to non-clinical personnel. ${ }^{19}$ On such occasions the concept of proportionality has an important application - the degree and extent of disclosure of information has to be proportionate to the nature of the presenting clinical situation. An assessment of the reasons for disclosing information is required and a balance must be reached between those reasons and the person's right to privacy and confidentiality.

\section{Equality}

The many facets to expressing the principle of equality, including non-discrimination, overlap with respect. The NHS itself was founded on the principle of equality: equity of access and equity of treatment. ${ }^{20}$ Moreover, the NHS Constitution $^{21}$ lists equality first among the seven key principles that guide the NHS. Differences in clinical need have to be determined through procedures that remove arbitrariness from the decision-making process.

The Commission for Equality and Human Rights was established under the Equality Act 2006, which gave it the legal responsibility to tackle discrimination and promote equality on the grounds of disability, gender and race. The Commission has a statutory general duty to encourage and support the development of a society in which, inter alia, 'each individual has an equal opportunity to participate' (Section 3). The Act does not specifically mention 'mental health' and the phrase is also absent from the Commission's Equality Scheme 2008/09, ${ }^{22}$ although one would assume that those diagnosed with mental disorders are contemplated when the Commission espouses responsibilities to 'promote equality of opportunity between disabled people and others' and in promoting 'positive attitudes towards disabled people'. The Commission will also want to have regard to the College's manifesto, 'Fair Deal for Mental Health', in tackling inequality in mental healthcare and in particular discrimination and stigma, which is one of the eight priority areas of this 3-year campaign. ${ }^{23}$

\section{Clinical implications}

Discrimination occurs when someone is treated in a different way to someone else in a similar situation, or where people in very different situations are treated the same. An action or decision is considered discriminatory if it cannot be reasonably and objectively justified. Such a case was the subject of a House of Lords judgment ${ }^{24}$ whereby a restrictive interpretation of the 'public function' provision in the Human Rights Act meant those managing care homes or delivering privatised or contracted out public services did not have to have regard to the standards of care, treatment and procedural protection of residents expected as if they had been delivering a 'pure' public function, such as in an NHS establishment. An amendment in the Health and Social Care Act 2007 brought an end to this inequitable situation between the public and private sectors. 
The Disability Rights Commission reported on inequalities in the healthcare provided to people with mental health problems or intellectual disabilities compared with the general population. ${ }^{25}$ These groups were found to be less likely to receive some standard, evidence-based health checks and treatments (such as health screening or statin treatment) as well as facing access and attitude barriers in using health services.

Individuals with mental disorders remanded in custody or serving terms of imprisonment are recognised as being at a higher risk of receiving a lower standard of mental healthcare than their counterparts in the community. The Joint Committee on Human Rights has underscored the importance of the principle of equivalence between prison healthcare and that enjoyed by the wider community:

'The principle of equal treatment is the fundamental underlying notion of human rights. That equality of treatment should be upheld in relation to mental healthcare as well as in relation to physical healthcare is, therefore, not only an unsurprising, but a necessary component of compliance with the positive obligation to protect Convention rights under Articles 8, 3 and 2 ECHR. ${ }^{26}$

However, the Committee was also careful to warn that better prison mental healthcare 'should not be used as a substitute for care and treatment in NHS facilities'.

\section{Dignity}

The importance of human dignity has been emphasised in international human rights instruments from the Universal Declaration of Human Rights (Article 1) in 1948 onwards. In the United Nations Convention on the Rights of Persons with Disabilities, dignity is the only principle specifically mentioned in the Statement of Purpose (Article 1). In 2004, the Council of Europe issued recommendations to member states pertaining to the protection of human rights and specifically the dignity of persons with mental disorders. ${ }^{27}$ The UK, however, opted out on certain recommendations because it knew the Mental Health Act Amendments 2007 and the Mental Capacity Act 2005 would eventually not be fully compliant with the recommendations as a whole. ${ }^{28}$ Although 'dignity' is not explicitly mentioned in the ECHR, it is said to be implicit in almost every one of the Convention's articles and, following the introduction of the Human Rights Act, the principle of dignity has been accorded prominence in domestic jurisprudence: 'The recognition and protection of human dignity is one of the core values - in truth, the core value - of our society and, indeed, of all societies... of the European family of nations... which have embraced the principles of the (European) Convention (on Human Rights)', and furthermore, 'The invocation of the dignity of the patient... is a solemn affirmation of the law's and of society's recognition of our humanity and of human dignity as something fundamental. ${ }^{29}$

Dignity has been defined as 'a state, quality or manner worthy of esteem or respect; and (by extension) self-respect. Dignity in care, therefore, means the kind of care, in any setting, which supports and promotes, and does not undermine, a person's self-respect regardless of any difference. ${ }^{3}$ By extrapolation, dignity can be regarded as arising from a dynamic between a person's own sense of worth and the manner in which others treat them. ${ }^{30}$ Adherence to the principle of dignity requires that each person is treated as a human being with due consideration given to their prevailing circumstances. By this criterion the person's level of consciousness is immaterial and the principle of dignity must be upheld even after death, for example, by having proper procedures in place to regulate the retention of human tissue after a post-mortem.

\section{Clinical illustrations}

Article 3 of the ECHR prohibits torture, or inhuman or degrading treatment or punishment, and this might be seen as only relevant to prisoners of war in combat conditions far removed from healthcare settings. The European Court of Human Rights has set a high threshold before particular cases can be considered to violate Article 3 (e.g. Herczegfalvy). ${ }^{31}$ It is often said that European human rights jurisprudence sets a floor and not a ceiling to standards of care. By contrast, a human rights-based approach aims to raise standards through a 'bottom-up' approach, which demonstrates that simply avoiding engagement with Article 3 does not guarantee a good-enough level of healthcare. In other words, to ensure that everyone is treated with dignity, the approach of a good health service or a worker in that service needs to be aimed at preserving dignity, rather than retreating from whatever level of indignity the law is prepared to tolerate. Poor care that could potentially engage Article 3 issues can be represented on a spectrum from physical abuse, excessive restraint and neglect $^{32}$ to malnutrition and dehydration resulting from (unintentionally) leaving meal trays out of reach of infirm, bed-bound patients who cannot feed themselves. Characteristics of organisations which permit abusive practice to develop unchecked include geographical isolation and an introspective culture, quantitative and qualitative staffing difficulties, a lack of training and supervision, and weak organisational and local leadership. ${ }^{33}$

In clinical settings, dignity issues can be subdivided into those concerning primarily the person and matters relevant to the environment the person is in. In the former category, affronts to dignity could result from referring to the person only by their diagnosis; by neglecting their appearance or state of dress, for example leaving them in soiled clothing or bed linen; or adopting an overly paternalistic or 'infantilising' approach to adults because of actual or assumed incapacity.

Environmental shortcomings can also have an impact on a person's dignity. Threats to dignity can range from having a lack of privacy in mixed-gender wards to having to live in impoverished, unclean or even dangerous environments. Conditions of privacy, whether it is while attending to toileting and personal care or during family visits or clinical consultations, may be jeopardised in settings where a greater priority is afforded to organisational efficiency than to individual care. The Joint Committee on Human Rights noted that over a fifth of care homes in England were failing to meet national minimum standards for privacy and dignity. ${ }^{34}$ Such failures may amount to violations of the right to respect for private and family life under Article 8 of 
the ECHR. 'Benchmarks' to promote dignity and privacy in person-centred clinical practice have been promulgated through the Department of Health 'Essence of Care' campaign. $^{35}$

\section{Autonomy}

Autonomy is regarded as one of the four fundamental ethical principles of healthcare. ${ }^{36}$ It is the principle of selfdetermination whereby a person is allowed to make free choices about what happens to them, that is, the freedom to act and the freedom to decide, based on clear, sufficient and relevant information and opportunities to participate in the decision-making.

Medical case law has consistently upheld the primacy of the choice of a person with capacity to make decisions regarding treatment. ${ }^{37}$ This principle is now embedded in statute in the Mental Capacity Act 2005 (the starting point being the rebuttable presumption that a patient has capacity); the principle of autonomy is also implicit in several of the rights of the ECHR. There have been legal challenges to the Mental Health Act's recognition that refusal of mental health treatment by a detained patient with capacity can be overridden (see $R$ (on the application of Wilkinson) $^{38}$ and $R$ (on the application of $\left.B\right)^{39}$ ). Some commentators have gone further and advocated capacitybased mental health legislation. ${ }^{40,41}$ However, to date, although the domestic courts have given some ground, they have not regarded this provision as violating the ECHR. Indeed, existing European jurisprudence, with its reliance on 'therapeutic necessity' (e.g. Herczegfalvy $v$. Austria, ${ }^{31}$ treatment demonstrated to be a 'therapeutic necessity' is unlikely to breach Article 3), would seem to sanction the present position in the Mental Health Act.

In clinical practice it is well recognised that a person's capacity to make decisions may be absent or compromised temporarily. The Mental Capacity Act 2005 has codified earlier case law and now permits a person to stipulate, while they have capacity, their future wishes regarding their healthcare (as well as matters regarding their property and affairs) in anticipation of a time when they will no longer have capacity. Such advance decisions allow a person to refuse certain treatments, including life-sustaining treatment, and so are vehicles whereby a degree of autonomy can survive the loss of capacity. Even in the absence of capacity, healthcare professionals should strive to ensure the person participates in the decision-making process as much as they are able. The participation principle in the Mental Health Act 1983 Code of Practice notes that 'patients must be given the opportunity to be involved, as far as is practicable in the circumstances, in planning, developing and reviewing their own treatment and care to help ensure that it is delivered in a way that is as appropriate and effective for them as possible'. ${ }^{11}$ In the same vein, the Mental Capacity Act 2005 requires that a person, even if lacking in capacity, is encouraged 'so far as reasonably practicable ... to participate ... as fully as possible in any act done for him and any decision affecting him' (Section 4).

Clinical implications

Protection from interference in private and family life is afforded by Article 8 of the ECHR. This is a qualified right meaning the state is permitted to limit the exercise of the right if certain conditions are met. However, an overly paternalistic style of care could also have impact on an individual's ability to exercise their choices. An investigation into services for people with intellectual disabilities ${ }^{32}$ noted they were 'generally "looked after" instead of being supported to develop their skills. This limited their ability to make informed choices and communicate their needs'.

Autonomy incorporates a sense of independence of actions as well as having control over one's choices and wishes. With advancing years a degree of dependence on others for assistance with daily activities may be common, but a move to a care home may also be delayed by the provision of extra support that enables the person to retain sufficient independence to continue living in their own home. This will, however, be accompanied by significant resource implications. The provision of relevant information and advocacy support is important in giving the person the knowledge with which to make decisions and exercise choice.

Such an 'enabling culture' should not cease once the person is admitted to the care home. They should be encouraged to continue to use their skills and develop new experiences even after they have left their original home. Conversely, some mental health patients may need protracted periods of in-patient care which can also be potentially de-skilling. A vital part of discharge planning is attention to the rehabilitation of skills necessary for community living. The 'recovery model' aims to personally empower those experiencing mental ill health and to promote optimal but realistic functioning. ${ }^{42}$

\section{Conclusions}

It has been claimed that, despite the enactment of the Human Rights Act, the general understanding of human rights has not progressed from legal concepts into values that could meaningfully inform the decision-making processes within provider organisations or positively enhance the experience of service users. ${ }^{43,44}$ However, it has also been found that "the term "human rights" had mainly positive associations... but there is little understanding of the application of human rights/the (Human Rights Act) to normal life (or) public service delivery'. ${ }^{45}$ In other words, although there is widespread uncertainty about the role and the impact of the Human Rights Act, there is also general agreement on the need for a human rights-based 'values' system for contemporary society.

This paper set out to illustrate that although human rights principles already underpin good healthcare, be it in psychiatry or any other branch of medicine, to articulate health service organisation and healthcare delivery in such terms remains novel. Although the concept of a human rights-based approach might be easier to comprehend than the technical operation of the Human Rights Act, the challenge still remains of rooting such principles into the everyday working practices of frontline clinical staff or into the decision-making processes of the boards of public and private providers of healthcare. Such a challenge is implicitly underpinned by the need for appropriate and 
suitably resourced training to be made available to such frontline staff and organisations as a whole. ${ }^{27}$

The Joint Committee on Human Rights has been critical of the government for its past failure of leadership in actively promoting a human rights culture and called on the Department of Health to 'maintain the clear political leadership that it has recently shown on the importance of human rights in health and social care' ${ }^{34}$ The Expert Committee on reform of the Mental Health Act argued the guiding principles should be on the face of the new act, to endow them with a prominence commensurate with their importance. ${ }^{40}$ The government were never in favour of such a stance and the guiding principles for the Mental Health Act are now to be found in the Code of Practice. ${ }^{11}$ The consultation on a Constitution for the $\mathrm{NHS}^{46}$ offered an opportunity to 'publicly champion an understanding of how the recognition of human rights principles can underpin a transformation of health and social care services'. However, individual healthcare professionals, working in accordance with their profession's codes of practice, have the daily opportunity to demonstrate human rights principles in practice by offering healthcare that epitomises the values of fairness, respect, equality, dignity and autonomy.

\section{About the authors}

Martin J. Curtice is Consultant in Old Age Psychiatry at Hollyhill Unit, Rubery, Birmingham, and Tim Exworthy is Consultant Forensic Psychiatrist at Memorial Hospital, Oxleas NHS Foundation Trust, London.

\section{References}

1 Department of Health. Human Rights in Healthcare: A Framework for Local Action. Department of Health, 2007.

2 Department of Health. National Service Framework for Older People. Department of Health, 2001.

3 Cass E, Robbins D, Richardson A. Dignity in Care: Adults' Services Practice Guide 9. Social Care Institute for Excellence, 2006.

4 Age Concern England. On the Right Track? A Progress Review of the Human Rights of Older People in Health and Social Care. Policy Unit, Age Concern England, 2008.

5 Department of Health. Medical Revalidation: Principles and Next Steps: The Report of the Chief Medical Officer for England's Working Group. Department of Health, 2008 (http://www.dh.gov.uk/en/Publications andstatistics/Publications/PublicationsPolicyAndGuidance/DH_ 086430).

6 Royal College of Psychiatrists. Good Psychiatric Practice (3rd edn) (College Report CR154). Royal College of Psychiatrists, 2009.

7 HL v. The United Kingdom (2004) Application no. 45508/99, Judgment 5th October; HL v. UK [2004] 1 FLR 1019.

8 Ministry of Justice. Mental Capacity Act 2005 Deprivation of Liberty Safeguards: Code of Practice to Supplement the Main Mental Capacity Act 2005 Code of Practice. TSO (The Stationery Office), 2008.

9 Lord Chancellor's Department. Mental Health Review Tribunal Rules 1983. Statutory Instrument 1983/942. Lord Chancellor's Department, 1983.

10 Randers I, Mattiasson AC. Autonomy and integrity: upholding older adult patients' dignity. J Adv Nurs 2004; 45: 63-71.

11 Department of Health. Code of Practice Mental Health Act 1983. TSO (The Stationery Office), 2008.

12 General Medical Council. Consent: Patients and Doctors Making Decisions Together. Guidance for Doctors. GMC, 2008.
13 Royal College of Psychiatrists. Good Psychiatric Practice (2nd edn) (College Report CR125). Royal College of Psychiatrists, 2004.

14 Royal College of Psychiatrists. Vulnerable Patients, Safe Doctors: Good Practice in Our Clinical Relationships (College Report CR146). Royal College of Psychiatrists, 2007.

15 Wicks E. Human Rights and Healthcare. Hart Publishing, 2007.

16 Pretty v. United Kingdom (2002) 35 EHRR 1.

17 Department of Health. Human Rights in Healthcare: A Framework for Local Action (2nd edn). Department of Health, 2008.

18 Z v. Finland (1997) Application no. 9/1996/627/811, Judgment 25th January.

19 General Medical Council. Confidentiality: Protecting and Providing Information. GMC, 2004

20 Department of Health. Promoting Equality and Human Rights in the NHS: A Guide for Non-Executive Directors of NHS Boards. Department of Health 2005 .

21 Department of Health. The NHS Constitution: The NHS Belongs to Us All. Department of Health, 2009.

22 Equality and Human Rights Commission. Our Equality Scheme 2009-12. Evidence, Actions, Results. EHRC, 2009 (http://www. equalityhumanrights.com/uploaded_files/equality_scheme_200912.pdf).

23 Royal College of Psychiatrists. Fair Deal for Mental Health. Royal College of Psychiatrists, 2008.

24 YL v. Birmingham City Council \& Ors [2007] UKHL 27.

25 Disability Rights Commission. Equal Treatment: Closing the Gap. DRC, 2007.

26 House of Lords and House of Commons Joint Committee on Human Rights. Deaths in Custody. Third Report of Session 2004-05. HL Paper 15-1, HC 137-1. TSO (The Stationery Office), 2004.

27 Council of Europe. Recommendation Rec (2004)10 of the Committee of Ministers to Member States Concerning the Protection of the Human Rights and Dignity of Persons with Mental Disorder. Council of Europe, 2004 (https://wcd.coe.int/ViewDoc.jsp?id=775685\&Site=CM\&BackColor Internet $=9999 \mathrm{CC} \&$ BackColorIntranet $=$ FFBB55\&BackColorLogged $=$ FFAC75).

28 Council of Europe. Recommendation 2004(10) Concerning the Protection of the Rights and Dignity of Persons with Mental Disorder. Further Statement by the United Kingdom Overtaking Statement Made on the Adoption of the Recommendation. Council of Europe (https:// wcd.coe.int/com.instranet.InstraServlet?Command=com.instranet. CmdBlobGet\&Docld=763898\&SecMode $=1 \& A d m i n=0 \&$ Usage $=2 \&$ InstranetImage=1025689).

$29 R$ (on the application of $A \&$ Ors) v. East Sussex County Council \& Anor [2003] EWHC 167 Admin.

30 Haddock J. Towards further clarification of the concept of 'dignity'. J Adv Nurs 1996; 24: 924-31.

31 Herczegfalvy v. Austria [1992] 15 EHRR 437.

32 Commission for Healthcare Audit and Inspection. Joint Investigation into the Provision of Services for People with Learning Disabilities at Cornwall Partnership NHS Trust. Healthcare Commission, Commission for Social Care Inspection, 2006

33 Commission for Health Improvement. Investigation into Matters Arising from Care on Rowan Ward, Manchester Mental Health and Social Care Trust. TSO (The Stationery Office), 2003.

34 House of Lords and House of Commons Joint Committee on Human Rights. The Human Rights of Older People in Healthcare. Eighteenth Report of Session 2006-07. Vol. 1: Report and Formal Minutes. TSO (The Stationery Office), 2007

35 Department of Health. Essence of Care: Benchmarks for the Care Environment. Department of Health, 2007.

36 Beauchamp TL, Childress JF. Principles of Biomedical Ethics (5th edn). Oxford University Press, 2001.

37 Re F (Mental Patient: Sterilisation) [1990] 2 AC 1; Re T (Adult: Refusal of Treatment) [1993] Fam. 95; Re MB (Medical Treatment) [1997] 2 FLR 426. 
$38 R$ (on the application of Wilkinson) v. (1) The RMO, Broadmoor Hospital (2) The Mental Health Act Commission Second Opinion Appointed Doctor and Secretary of State for Health (interested party) [2001] EWCA Civ 1545; [2002] 1 WLR 419.

$39 R$ (on the application of B) $v$. (1) Dr SS Responsible Medical Officer, Broadmoor Hospital (2) Dr G Second Opinion Appointed Doctor (3) Secretary of State for the Department of Health [2005] EWHC 1936 Admin.

40 Department of Health. Report of the Expert Committee: Review of the Mental Health Act 1983. TSO (The Stationery Office), 1999.

41 Szmukler G, Holloway F. Reform of the Mental Health Act. Health or safety? Br J Psychiatry 2000; 177: 196-200.
42 Roberts G, Wolfson P. The rediscovery of recovery: open to all. Adv Psychiatr Treat 2004; 10: 37-48.

43 Audit Commission. Human Rights: Improving Public Service Delivery. Audit Commission, 2003.

44 British Institute of Human Rights (2002) Something for Everyone: The Impact of the Human Rights Act and the Need for a Human Rights Commission. British Institute of Human Rights (http://www.bihr.org.uk/ sites/default/files/something_for_everyone.pdf).

45 Ministry of Justice. Human Rights Insight Project. Ministry of Justice Research Series 1/08. Ministry of Justice, 2008.

46 Department of Health. The National Health Service Constitution. A Draft for Consultation. Department of Health, 2008. 